\title{
Influence of the laser welding process on changes in the magnetic induction of the Religa Heart ROT pump
}

\author{
Sebastian Stano ${ }^{1, *}$, Roman Kustosz² ${ }^{2}$ Artur Kapis², Przemysław Kurtyka² ${ }^{2}$ Jerzy Zalewski², \\ Magda Zarwańska ${ }^{2}$ \\ ${ }^{1}$ Łukasiewicz Research Network - Welding Institute, Gliwice, Poland; \\ 2 Fundacja Rozwoju Kardiochirurgii im. prof. Zbigniewa Religi, Zabrze, Poland; \\ Roman Kustosz; romankustosz@FCSD.pl \\ Artur Kapis; akapis@FCSD.pl \\ Przemysław Kurtyka; pkurtyka@FCSD.pl \\ Jerzy Zalewski; jerzyzalewski@FCSD.pl \\ Magda Zarwańska; zarwanska@FCSD.pl \\ * Correspondence: Dr. Sebastian Stano; sebastian.stano@is.gliwice.pl
}

\begin{abstract}
The study addresses the results concerning the laser welding technology of the titanium circulatory support blood pump Religa Heart ROT. Pulse laser welding parameters were determined and selected. The influence of the pulse welding parameters and other conditions of welding process on the magnetic induction distribution of the mechanical circulatory support blood pump was investigated.
\end{abstract}

Keywords: pulse laser welding; titanium alloys laser; magnetic induction distribution

\section{Introduction}

The Foundation of Cardiac Surgery Development in Zabrze (FCSD), The Artificial Heart Laboratory, conducts intensive work on the construction and manufacture of a cardiac support pump. Previously used national cardiac pumps are extracorporeal pumps, which means that a patient waiting for a heart transplant in a hospital ward must be present and be uncomfortably discharged during simple daily activities. Religa Heart ROT is a miniature centrifugal pump, implanted through the tip directly into the left ventricle of the heart, which allows it to be placed in the pericardial sac just in the vicinity of the heart. It pumps blood from the left ventricle to the aorta thanks to the spinning of a miniature rotor (closed channels) suspended in a static magnetic field and rotating at a rotational speed of 2,500 to 5,500 rpm thanks to the use of a variable magnetic field drive. This design of the pump ensures that the blood is pumped through the channels of the rotor, which circulates blood on all sides, eliminating the formation of local areas with an increased risk of thrombus formation [1].

One of the key elements of the RH ROT is the pump rotor, which is a multi-part construction that possesses permanent magnets that are extremely important for its proper operation, enabling the pump to rotate in a static magnetic field. Stable operation of the rotor is ensured by the use of two suspension systems: magnetic and hydrodynamic bearings, located in the upper and lower part of the rotor.

In the original design assumptions, the rotor elements were glued together. At present, due to the necessity of obtaining a permanent and tight connection, it has been decided to replace the parts of glued connections of the rotor with welded joints. The weld on the edges of the rotor should ensure high tightness of the connection, preventing the penetration of body fluids into the rotor. In addition, the use of additional finishing treatments, including polishing of the weld, will allow the removal of sharp edges that expose blood to traumatization.

\section{Pulse laser welding}

Laser welding of titanium alloys, along with classical TIG arc welding, is increasingly used in industry. Relatively small amounts of heat introduced into the joint in order to obtain a connection, compared to the TIG method, result in obtaining welds with much smaller face and root width and a very narrow heat affected zone. As in the case of arc welding, it is necessary to use a gas shield for a liquid pool and hot weld due to the high ease of absorption by most titanium alloys of gases from the surrounding atmosphere at temperatures above $300{ }^{\circ} \mathrm{C}[2 \div 19]$. The scope and method of the gas shield used depends directly 
on the laser welding parameters - the amount of heat input in the welding process, in particular on the laser operating mode - continuous mode or pulse mode.

The emission of a laser beam in pulse mode means that the energy necessary to melt the material and create a weld is delivered to the material not continuously, but intermittently at a certain frequency. The continuous weld produced by the laser beam emitted in pulse mode consists of a series of overlapping spot welds. One pulse creates a single spot weld. The pulse repetition frequency should be chosen so that the new spot weld created after the previous joint solidifies. If the repetition frequency is too high, the pulse welding process may proceed as a continuous beam welding process, where a continuous gas channel or liquid weld pool is produced. The degree of overlapping of particular impulses determined in percent means to what extent the area melted by a single impulse overlaps a similar area produced by the previous impulse. With the help of the overlap, you can influence the uniformity of the weld structure and the effective penetration depth achieved (Fig. 1), as well as the roughness and aesthetic appearance of the weld face. The overlap depends on the welding speed, the diameter of the laser beam on the material and the frequency of repetition of pulses. In practice, a simplified formula (1) is used to calculate the welding speed $\mathrm{v}$ for the assumed $\mathrm{Z}$ overlap at a given diameter of the laser beam on the material $d$ and the repetition frequency $f p$ :

$$
v=d \cdot f_{p} \cdot\left(1-\frac{Z}{100}\right)
$$

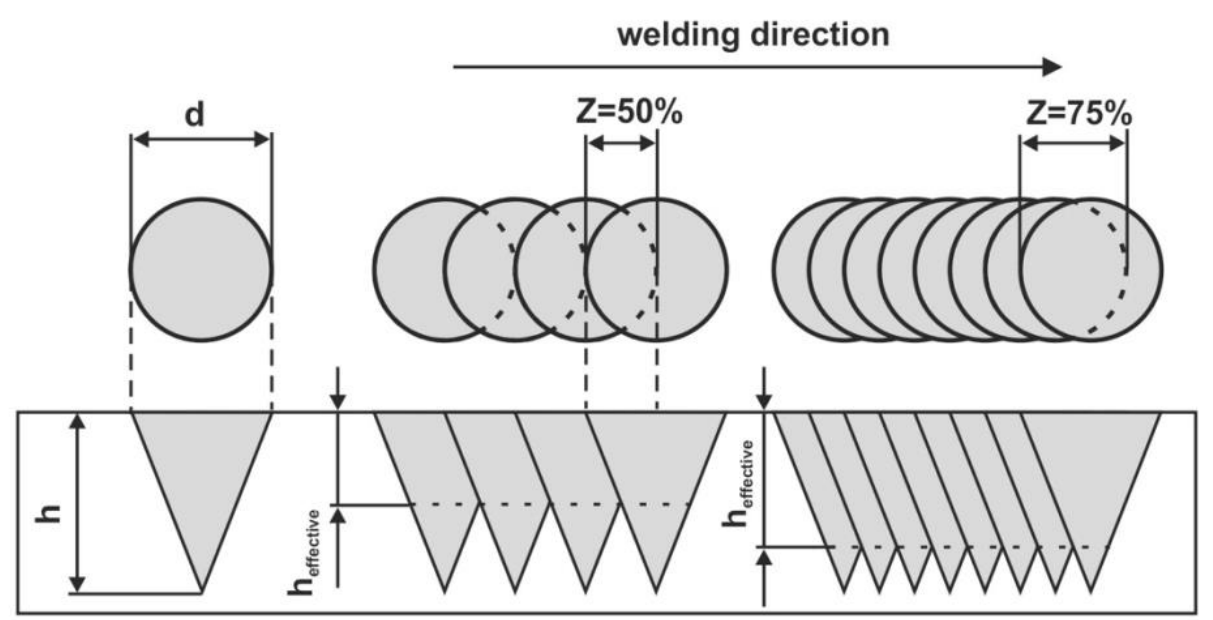

Fig. 1. Graphical interpretation of the laser beam pulse overlap and effective depth of penetration

With a fixed value of the overlap, for a given diameter of the laser beam on the material it is possible to obtain many pairs of welding speeds and repetition frequency of pulses, which result in theoretically obtaining the same depth of penetration. However, these parameters will differ in the average power obtained, which directly shows the amount of heat that is introduced in the process of joining the welded element (Fig. 2).

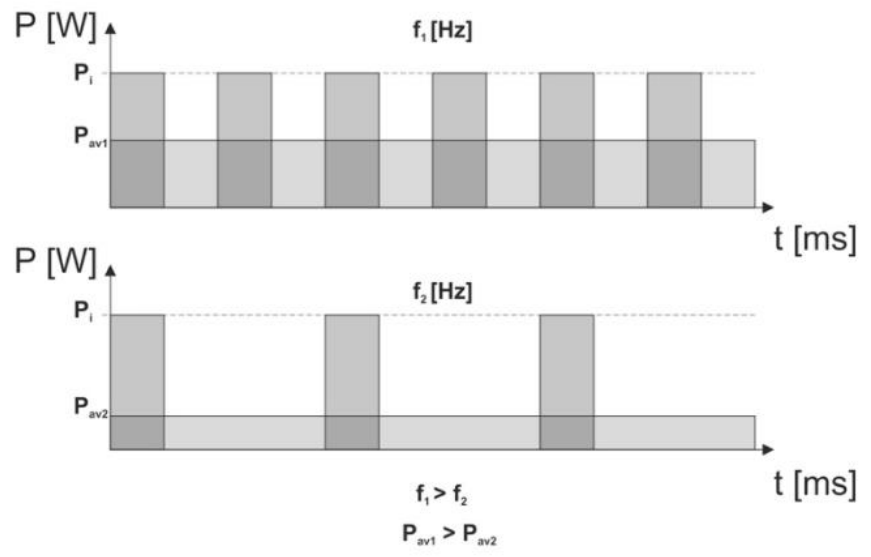

Fig. 2. Graphic comparison of the obtained average laser beam power with the same pulse parameters and at different repetition frequencies 


\section{Own research}

The aim of the research was to develop a laser welding technology for titanium elements of the RH ROT artificial heart pump rotor, including the choice of welding parameters ensuring: tightness of the connection without full remelting of the rotor wall and maximum limitation of the heat input due to the probable change in the magnetic field distribution of the rotor pumps as a result of the influence of the thermal cycle of welding.

\section{Workstation and materials for testing}

The laser welding tests were carried out using the TruLaser Station 5004 workstation installed in the Welding Institute with numerical control of the laser head positioning in three linear axes and a numerically controlled rotator (Fig. 3a). The TruPulse 103 laser resonator with a $95 \mathrm{~W}$ average power and a maximum pulse power of $6 \mathrm{~kW}$ is integrated with the TruLaser Station 5004. In the welding process, argon was used at a flow rate of $6 \div 8 \mathrm{l} / \mathrm{min}$ through a gas nozzle with a diameter of $8 \mathrm{~mm}$ with a gas lens ensuring a laminar flow of shielding gas. The setting of the gas nozzle (Fig. 3b) and the selected shielding gas flow ensured a stable welding process and no tarnish on the surface of the welded titanium rotor (Fig. 3c).

The rotor of the artificial heart pump RH ROT is a multi-part element made of Ti6Al7Nb titanium alloy with a specified biocompatibility, suitable for elements in contact with human tissue. Pump rotors for welding tests were delivered by the FCSD in a compound state. The outer rotor discs of the pump are covered with titanium nitride. Due to the high costs of obtaining the TiN coating, a part of the pre-welding tests were carried out on pump rotors without coating with titanium nitride. When attempting to weld discs with TiN coating, titanium nitride was mechanically removed from the contact area of the connected elements. The rotor of the pump was fixed with special brackets (separately for external and internal welds) in the machine's impeller. Initially, the horizontal angle of the rotor's rotary axis was $0^{\circ}$ for external welds and $17^{\circ}$ for internal welds, with the vertical direction of the laser beam propagating. In further studies, the inclination angle of the rotation axis for external welds was set at $12.5^{\circ}$ to direct the laser beam to a more massive rotor core element. Two external butt welds (ø34) and two internal perimeter seams (ø9) were made for one pump rotor (Fig. 4). Before delivery of the rotors for welding, the FCSD performed inductance distribution measurements for each rotor.

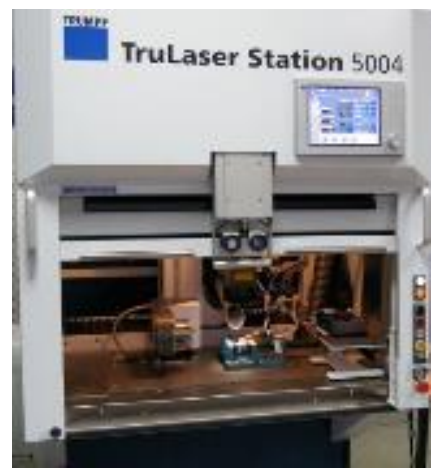

(a)

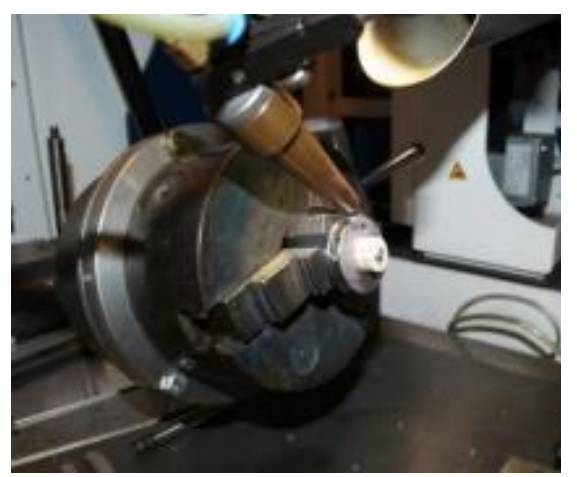

(b)

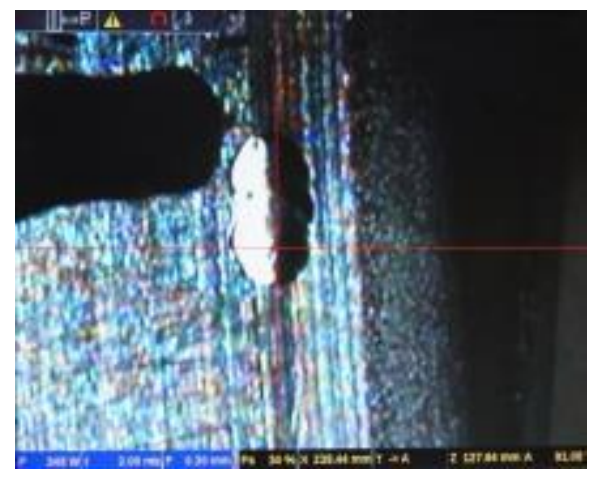

(c)

Fig. 3. a) TruLaser Station 5004 installed in the IS Laboratory of Laser Technology, b) test element mounted in the positioner's holder, c) monitor screen with the real image of the pulse welding process

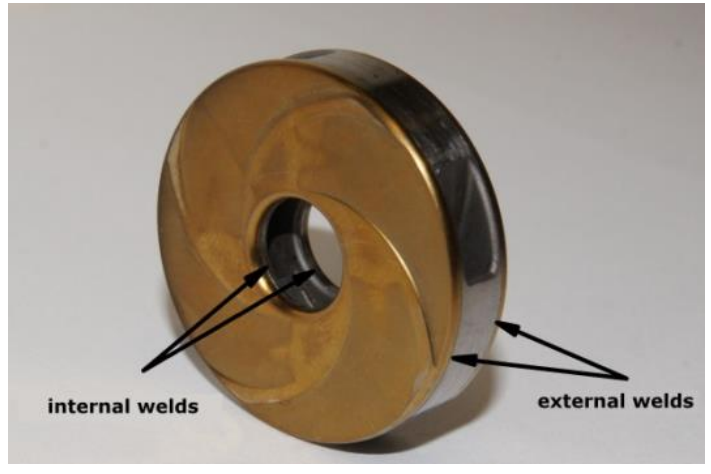

(a)

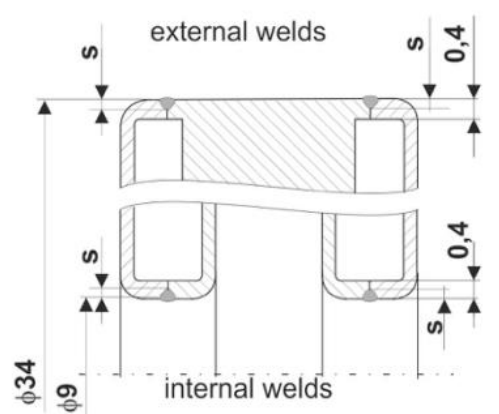

(b)

Fig. 4. a) rotor of the RH-ROT pump with marked locations of welds, b) scheme of assembly of the elements for welding 


\section{Research results and analysis}

In order to determine the effect of the pulse power on the obtained depth of penetration and changes in the magnetic field of the rotor, the test rotor was divided into four equal sectors (quarters). Sectors as well as external and internal welds made in these sectors are marked with letters A to D. A continuous weld overlap $\mathrm{Z}=75 \%$ and a pulse repetition frequency of $10 \mathrm{~Hz}$ were assumed. For the above parameters, the welding linear velocity $0.75 \mathrm{~mm} / \mathrm{s}$ was calculated, which was then converted into rotor's speed according to its external diameter $(0.41 \mathrm{rpm})$ and internal diameter $(1.6 \mathrm{rpm})$. Each of the sectors was made at a different setting of the maximum level of pulse power (Table I). After the welding tests, the rotor was transferred to the FCSD for measurements of the magnetic field strength of the rotor and their comparison with inductance measurements before welding. This way maps of the magnetic flux change distribution of the rotor were created as a result of the interaction of different thermal cycles of welding in individual sectors of the rotor (Fig. 5).

Analysis of the obtained magnetic induction maps showed that the applied welding parameters influence the magnetic induction of the rotor. The smallest decrease in magnetic induction was obtained in the rotor's sector A, i.e. the sector in which the smallest pulse power was applied - $350 \mathrm{~W}$ (medium power $\left.\mathrm{P}_{\mathrm{av}}=6.96 \mathrm{~W}\right)$. With the increase of the impulse power applied in particular sectors $\mathrm{B}, \mathrm{C}$ and $\mathrm{D}$, the percentage decrease in the magnetic induction as well as the area of the resulting changes increased. In sectors $\mathrm{D}$ (pulse power $\mathrm{P}=500 \mathrm{~W}$, medium power $\mathrm{Pav}_{\mathrm{av}}=9.96 \mathrm{~W}$ ), in the areas of external welds, declines in magnetic induction of $80 \div 100 \%$ were recorded. Taking into account the criterion of the smallest decrease in the magnetic induction of the rotor, the most preferred parameters were laser welding parameters used in sector A. Despite the use of low impulse power $(350 \mathrm{~W})$ in sector A, small areas of the rotor magnetic flux distribution maps were found in these sectors, in which a decrease in magnetic induction was obtained by approx. $20 \div 40 \%$.

Table I. Welding parameters used in individual sectors of the rotor

\begin{tabular}{|c|c|c|c|c|c|c|c|c|}
\hline Weld & $\begin{array}{c}\mathbf{P} \\
{[\mathbf{W}]}\end{array}$ & $\begin{array}{c}\mathbf{t} \\
{[\mathrm{ms}]}\end{array}$ & $\begin{array}{c}\mathbf{f} \\
{[\mathrm{Hz}]}\end{array}$ & $\begin{array}{c}\mathbf{n} \\
{[\mathrm{rev} / \mathrm{min}]}\end{array}$ & $\begin{array}{c}\mathbf{E} \\
{[\mathbf{J}]}\end{array}$ & $\begin{array}{c}\mathbf{P}_{\mathrm{av}} \\
{[\mathbf{W}]}\end{array}$ & $\begin{array}{c}\text { Angle } \\
{\left[{ }^{\circ}\right]}\end{array}$ & $\begin{array}{c}\text { Designation of sectors and lines } \\
\text { of intersection for metallographic } \\
\text { defects }\end{array}$ \\
\hline A external & 350 & 2 & 10 & 0.41 & 0.65 & 6.96 & 0.0 & \\
\hline $\mathrm{A}_{\text {internal }}$ & 350 & 2 & 10 & 1.60 & 0.65 & 6.96 & 17.5 & \\
\hline B external & 400 & 2 & 10 & 0.41 & 0.70 & 8.04 & 0.0 & \\
\hline$B_{\text {internal }}$ & 400 & 2 & 10 & 1.60 & 0.70 & 8.04 & 17.5 & \\
\hline Cexternal & 450 & 2 & 10 & 0.41 & 0.75 & 9.00 & 0.0 & \\
\hline $\mathrm{C}_{\text {internal }}$ & 450 & 2 & 10 & 1.60 & 0.75 & 9.00 & 17.5 & \\
\hline Dexternal & 500 & 2 & 10 & 0.41 & 0.80 & 9.96 & 0.0 & \\
\hline$D_{\text {internal }}$ & 500 & 2 & 10 & 1.60 & 0.80 & 9.96 & 17.5 & \\
\hline
\end{tabular}
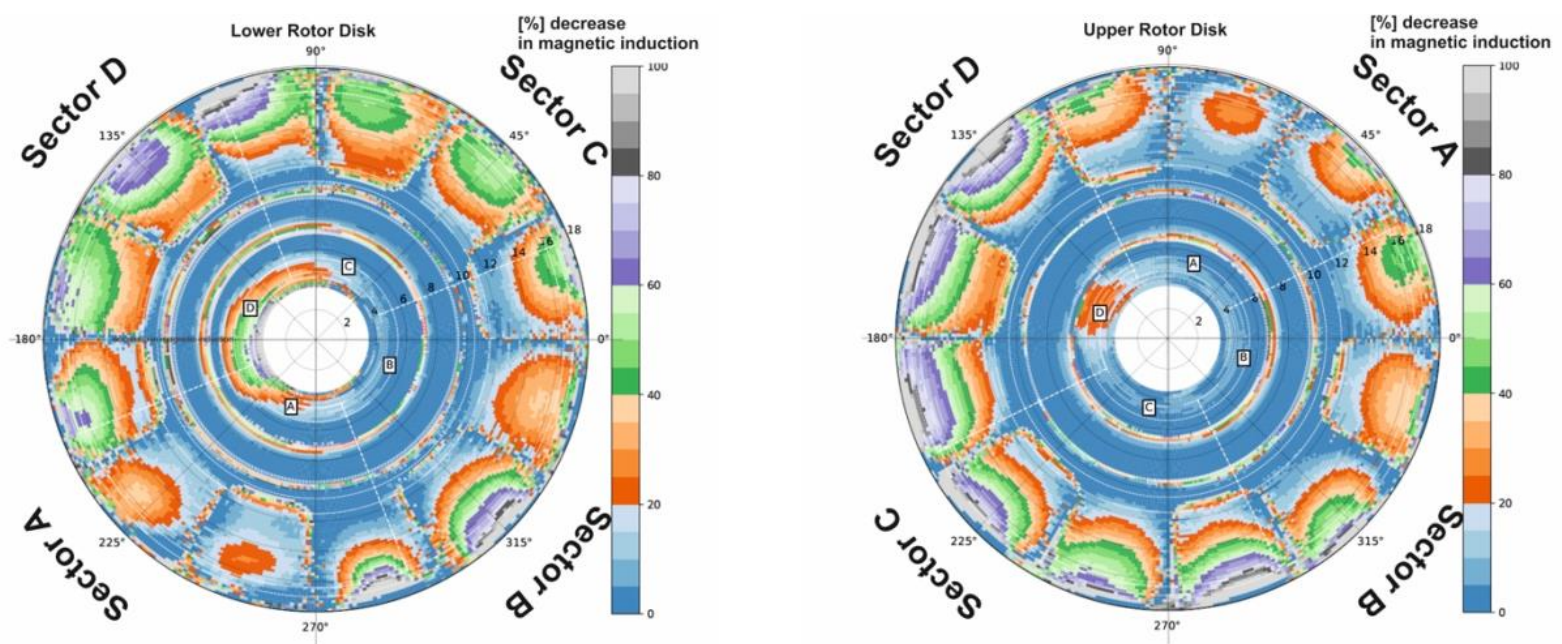

Rys. 5. Map of the distribution of changes in magnetic induction as a result of different heat cycles of welding in individual sectors. Welding parameters in individual sectors are shown in Table I 
In addition to the criterion of the smallest decrease in the magnetic induction of the rotor, it is also important to obtain the appropriate depth of penetration and weld tightness as well as the minimum roughness. In order to determine the obtained penetration depth for individual welding parameters, metallographic defects were performed in individual sectors by cutting the rotor along the cross-section lines marked in the figure in Table I. Four metallographic welds were obtained for individual sectors: two external welds and two internal welds (Fig. 6 $\div 9$ ).

Rotor's bottom disk

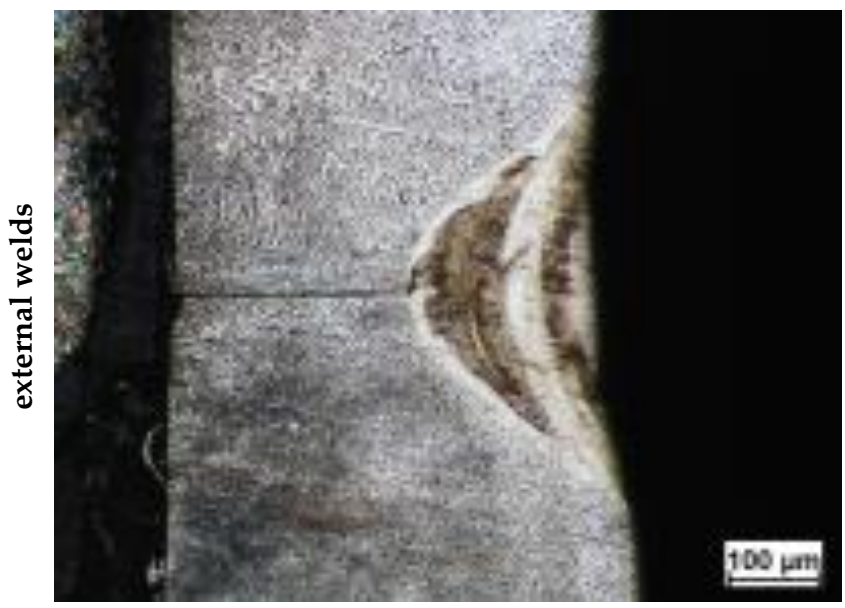

$\mathrm{WL}=0.455 \mathrm{~mm}, \mathrm{~h}=0.209 \mathrm{~mm}$

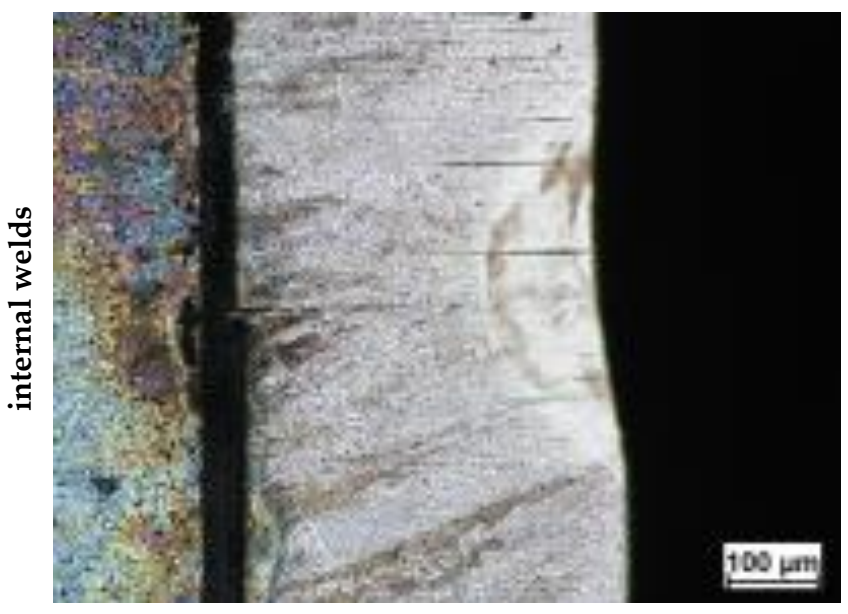

$\mathrm{WL}=0.437 \mathrm{~mm}, \mathrm{~h}=0.129 \mathrm{~mm}$
Rotor's upper disk

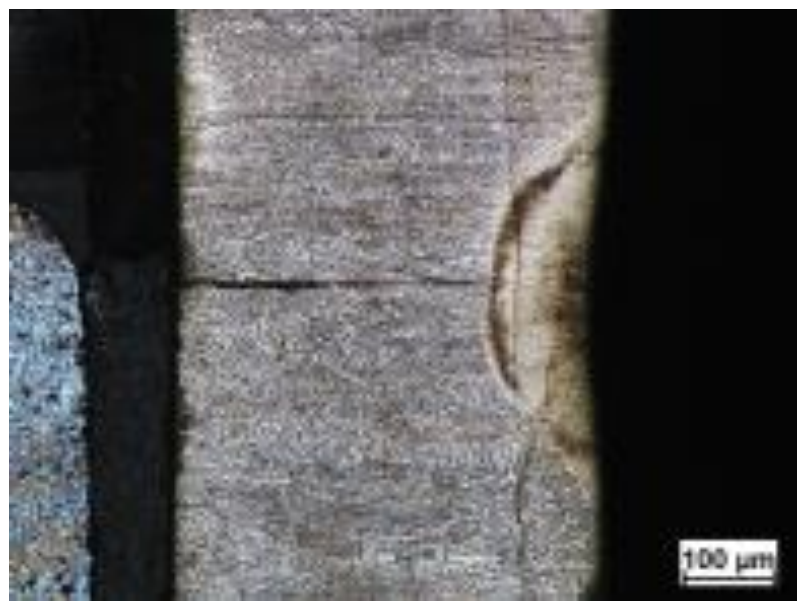

$\mathrm{WL}=0.455 \mathrm{~mm}, \mathrm{~h}=0.104 \mathrm{~mm}$

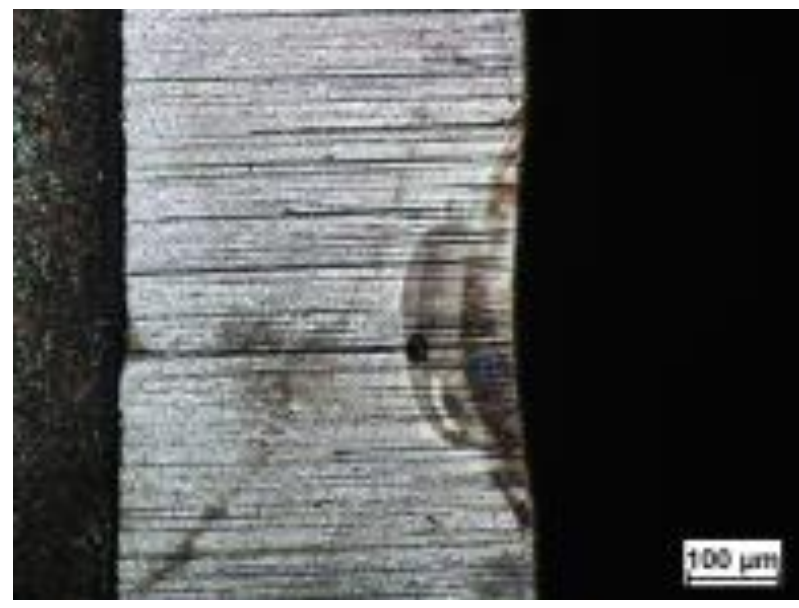

$\mathrm{WL}=0,455 \mathrm{~mm}, \mathrm{~h}=0.131 \mathrm{~mm}$

Fig. 6. Metallographic microsections and the results of measurements of the width of the face wh and depth of penetration $\mathrm{h}$ of external and internal joints of the pump rotor from sector A (Table I)

Analyzing the obtained penetration depths in individual rotor sectors, it was found that penetration obtained in sector A (minimum penetration was above $0.1 \mathrm{~mm}$ ) is sufficient for proper and safe operation of the pump. With the increase of the pulse power used in particular welding sectors, the depth of penetration increased, at the same time adversely affecting changes in the magnetization of magnets inside the rotor. Measurements of the weld face profile showed that the obtained face is smooth and the smallest roughness was characterized by welds from sector $\mathrm{A}$, in particular internal welds, which were made with the inclination of the rotor axis of the rotor by $17.5^{\circ}$.

An analysis of the selected laser welding parameters of the pump rotor was carried out. It has been found that further reduction of the pulse power and/or pulse duration, along with the reduction of the amount of heat introduced into the rotor, will result in a drop in the depth of penetration. This may result in leakiness of welds after surface treatment of the rotor.

Therefore, it has been proposed to perform the welding tests of the pump rotor while maintaining the power and duration parameters of the laser pulse as in sector A (Table I), while reducing the repetition rate of laser pulses. 


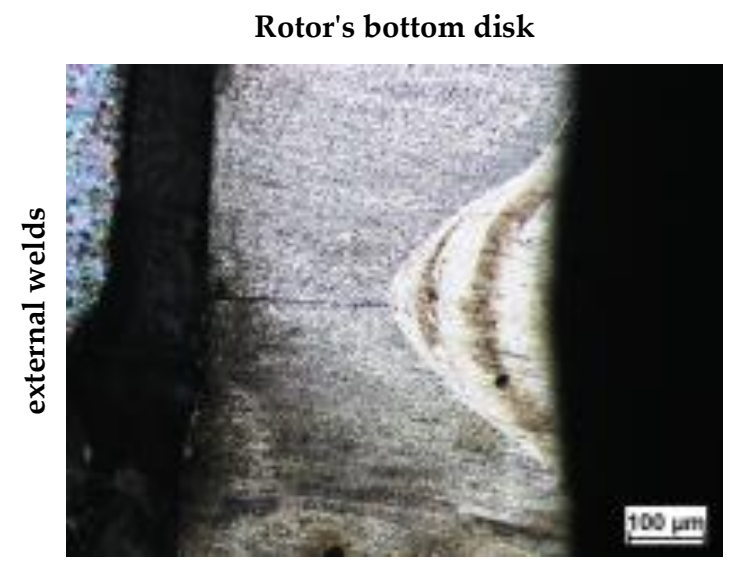

$\mathrm{WL}=0.455 \mathrm{~mm} ; \mathrm{h}=0.205 \mathrm{~mm}$

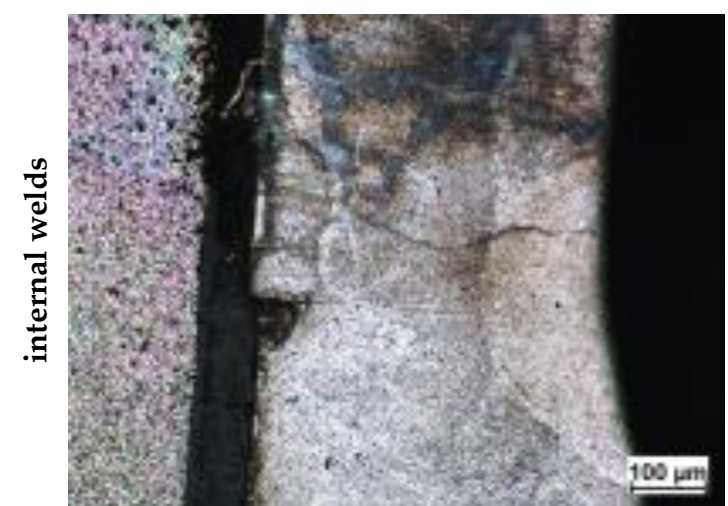

$\mathrm{WL}=0.467 \mathrm{~mm}, \mathrm{~h}=0.161 \mathrm{~mm}$
Rotor's upper disk

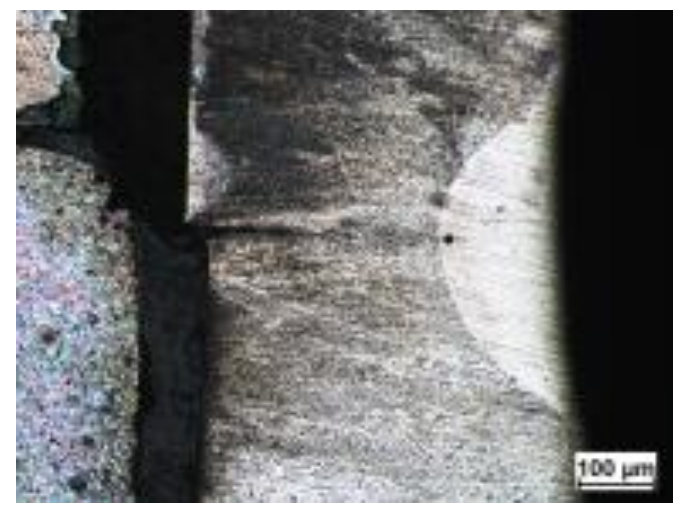

$\mathrm{WL}=0.483 \mathrm{~mm}, \mathrm{~h}=0.153 \mathrm{~mm}$

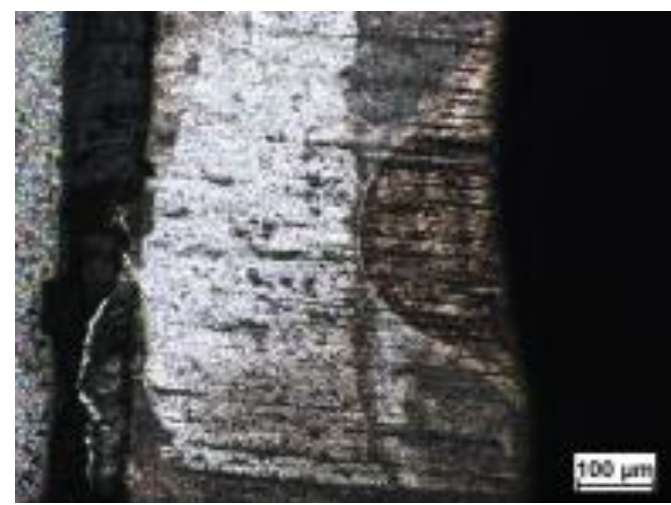

$\mathrm{WL}=0.473 \mathrm{~mm}, \mathrm{~h}=0.175 \mathrm{~mm}$

Fig. 7. Metallographic microsections and the results of measurements of the width of the face wL and depth of penetration $\mathrm{h}$ of external and internal joints of the pump rotor from sector B (Table I)

Rotor's bottom disk

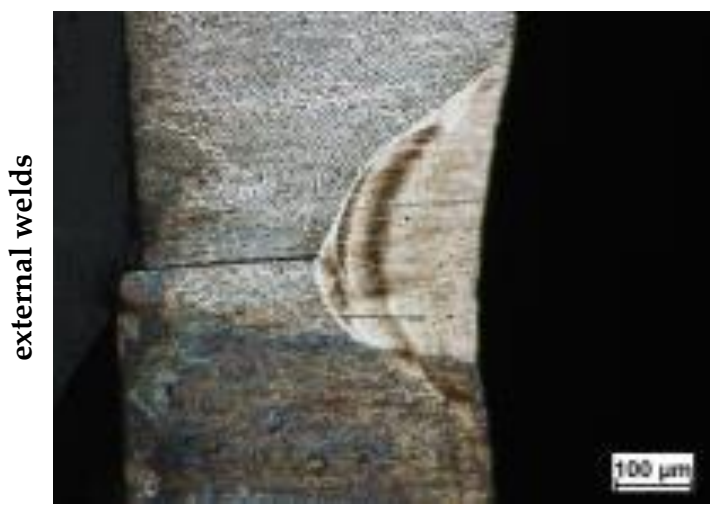

$\mathrm{WL}=0.537 \mathrm{~mm}, \mathrm{~h}=0.207 \mathrm{~mm}$

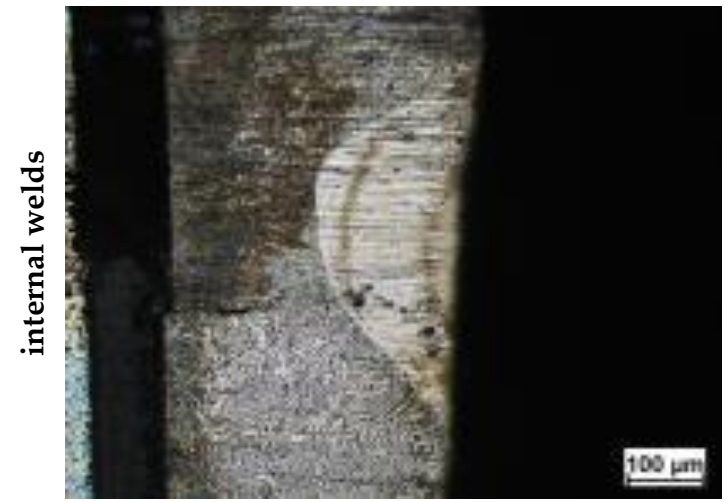

$\mathrm{WL}=0.447 \mathrm{~mm}, \mathrm{~h}=0.185 \mathrm{~mm}$
Rotor's upper disk

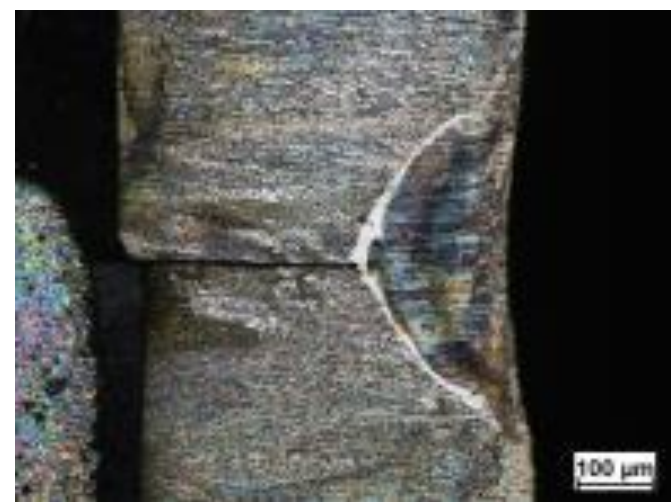

$\mathrm{WL}=0.513 \mathrm{~mm}, \mathrm{~h}=0.207 \mathrm{~mm}$

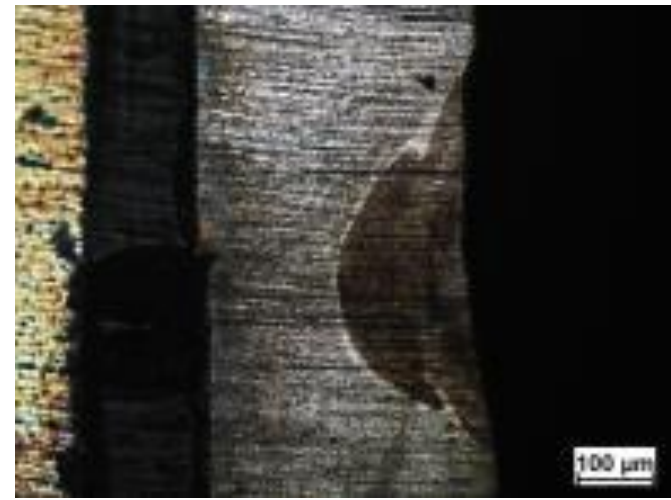

$\mathrm{WL}=0.483 \mathrm{~mm}, \mathrm{~h}=0.167 \mathrm{~mm}$

Fig. 8. Metallographic microsections and the results of measurements of the width of the face $\mathrm{WL}$ and depth of penetration $\mathrm{h}$ of external and internal joints of the pump rotor from sector C (Table I) 


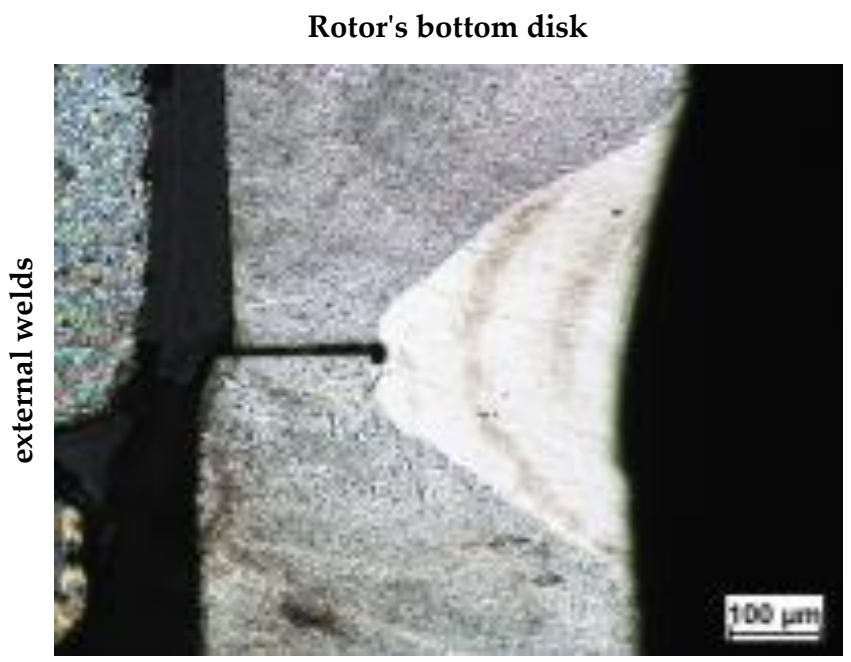

$\mathrm{WL}=0.522 \mathrm{~mm}, \mathrm{~h}=0.273 \mathrm{~mm}$

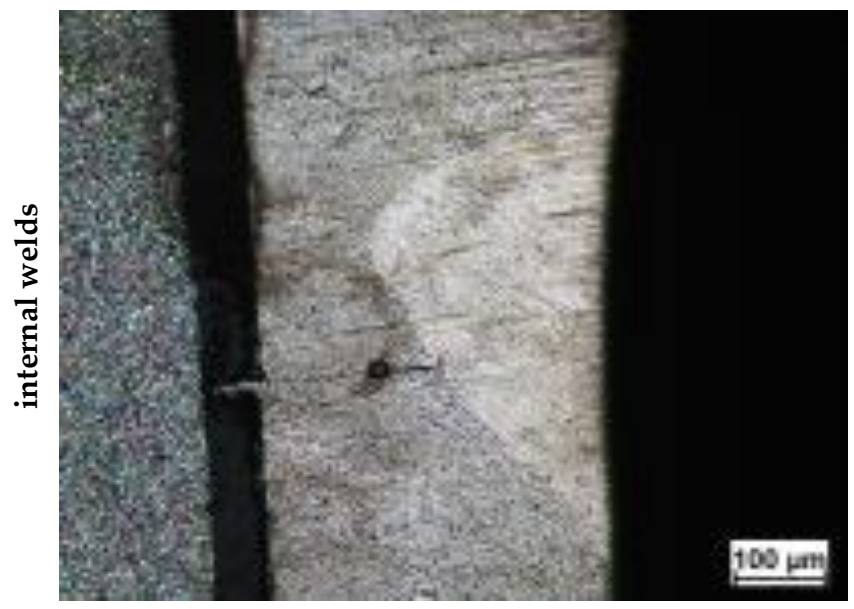

$\mathrm{WL}=0.471 \mathrm{~mm}, \mathrm{~h}=0.233 \mathrm{~mm}$
Rotor's upper disk

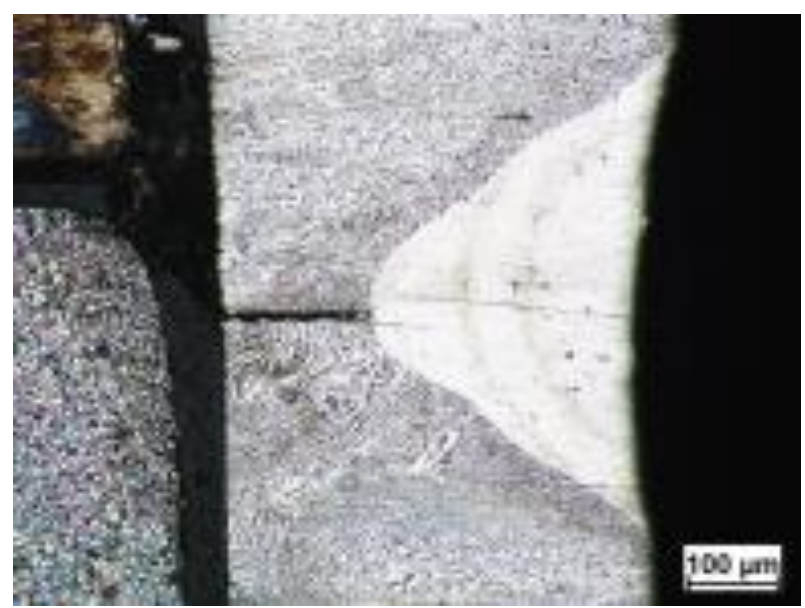

$\mathrm{WL}=0.527 \mathrm{~mm}, \mathrm{~h}=0.287 \mathrm{~mm}$

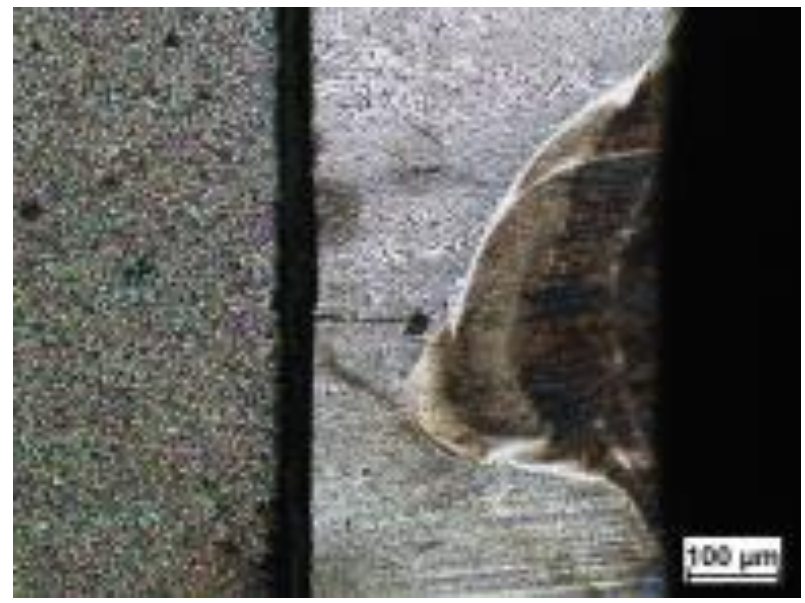

$\mathrm{WL}=0.567 \mathrm{~mm}, \mathrm{~h}=0.265 \mathrm{~mm}$

Fig. 9. Metallographic microsections and the results of measurements of the width of the face wL and depth of penetration $h$ of external and internal joints of the pump rotor from sector D (Table I)

The reduced frequency forces the rotor welding speed to be reduced to preserve the overlap of $75 \%$. The number of spot welds made on the perimeter of the rotor remains unchanged. The total amount of heat delivered during the execution of a single perimeter weld remains unchanged. However, the amount of heat entered per unit of time changes. This means that by extending the delivery time of the total energy needed to produce the entire weld, the accumulation of heat in the welding area can be reduced. Increasing the break time between laser pulses makes it possible to dissipate the heat delivered to the joint by thermal conduction into the rotor housing and exchange heat with the surrounding air rotor. Thus, the efficiency of the welding process decreases, which means that the welding of the rotor takes longer. This operation is effective only in the case of pulsed laser welding, where the penetration depth does not depend on the welding speed.

Calculations of rotor's rotational speed for external and internal welds were made, necessary to maintain $75 \%$ of the overlap using a pulse as in sector A for individual pulse repetition frequency values (Table II). During the testing of welding trajectory mapping, a hardware limitation was found regarding the possible stable rotational speed of the positioner, which resulted in a specific selection of repetition frequency.

Comparison of the obtained results of magnetic field measurements after welding to the results of magnetic field measurements of the rotor before welding allowed to obtain a map of the distribution of magnetic induction changes in particular welded sectors with different parameters of the laser welding process (Figure 10). It was found that in sectors A and B, during making the external and internal welds, there was no change in the inductance of the magnets inside the rotor. Small differences in the inductance appearing at the boundary of the magnets result from the inaccuracy of the measuring magnetic induction. 
Table II. Welding parameters used in individual sectors of the rotor with a reduced frequency of repetition of pulses

\begin{tabular}{|c|c|c|c|c|c|c|c|}
\hline Weld & $\begin{array}{c}\mathbf{P} \\
{[\mathbf{W}]}\end{array}$ & $\begin{array}{c}\mathbf{t} \\
{[\mathrm{ms}]}\end{array}$ & $\begin{array}{c}\mathbf{f} \\
{[\mathrm{Hz}]}\end{array}$ & $\begin{array}{c}\mathbf{n} \\
{[\mathrm{rev} / \mathrm{min}]}\end{array}$ & $\begin{array}{c}\mathbf{E} \\
{[\mathbf{J}]} \\
\end{array}$ & $\begin{array}{r}\mathbf{P}_{\mathrm{av}} \\
{[\mathrm{W}]}\end{array}$ & $\begin{array}{c}\text { angle } \\
{\left[{ }^{\circ}\right]}\end{array}$ \\
\hline $\mathrm{A} 81 / 83_{\text {zew }}$ & 350 & 2 & 1 & 0.04 & 0.65 & 0.65 & 12.5 \\
\hline A81/83 wew & 350 & 2 & 0.5 & 0.04 & 0.65 & 0.32 & 17.5 \\
\hline B81/83 zew & 350 & 2 & 2 & 0.04 & 0.65 & 1.3 & 12.5 \\
\hline B81/83 wew & 350 & 2 & 2 & 0.32 & 0.65 & 1.3 & 17.5 \\
\hline $\mathrm{C} 81 / 83_{\text {zew }}$ & 350 & 2 & 7 & 0.29 & 0.65 & 4.6 & 12.5 \\
\hline C81/83 wew & 350 & 2 & 4 & 0.64 & 0.65 & 2.6 & 17.5 \\
\hline D81/83 zew & 350 & 2 & 8 & 0.34 & 0.65 & 5.15 & 12.5 \\
\hline D81/83 $3_{\text {wew }}$ & 350 & 2 & 6 & 0.95 & 0.65 & 3.9 & 17.5 \\
\hline
\end{tabular}
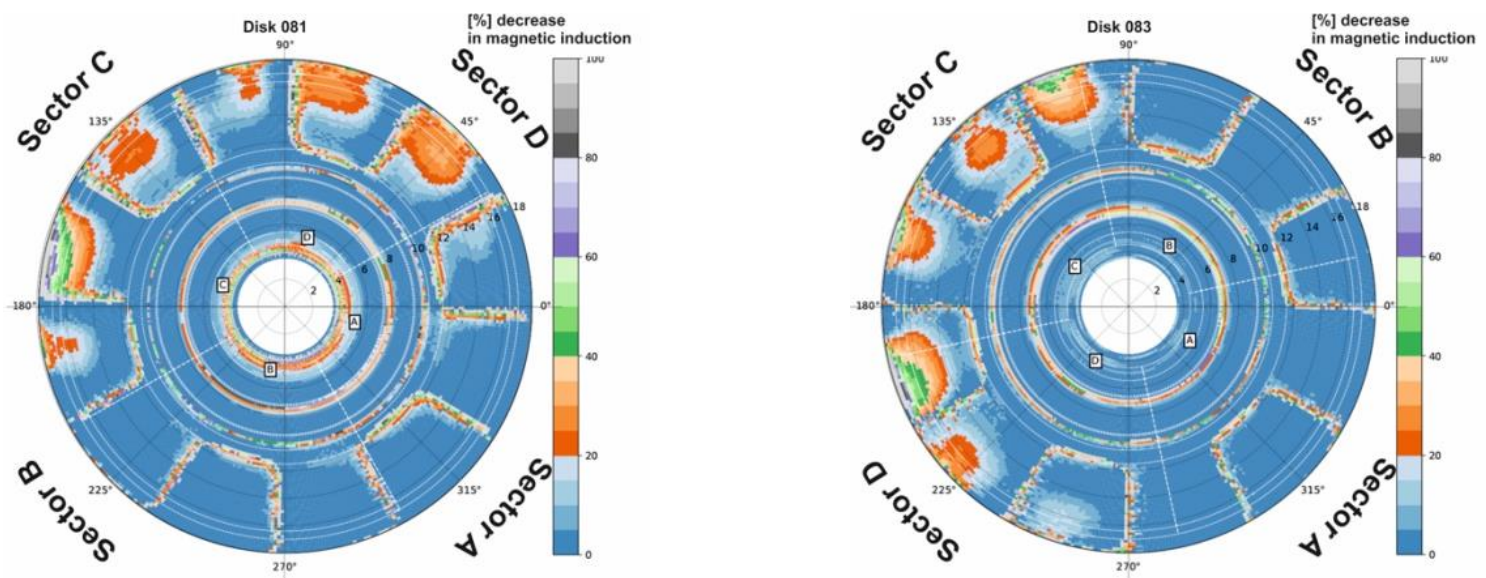

Fig. 10. Map of the distribution of changes in magnetic induction of the welded rotor with a reduced frequency of repetition of pulses. Welding parameters in individual sectors are shown in the table II

\section{Summary}

The slowdown of the pulse laser welding process, without affecting the penetration depth obtained, has a direct effect on the amount of heat introduced into the welded joint area. In the case of temperature-sensitive elements, e.g. due to the presence of neodymium magnets in the vicinity of the welds, lowering the welding frequency and thus welding speed allows to limit the average power transmitted to the welded element and significantly reduce the maximum temperature inside the welded element. Lowering the welding speed and impulse frequency in the welding process of the RH-ROT pump rotor made it possible to achieve the desired effect - connecting with maintaining metallic continuity over the entire length of the welded joint and preserving the magnetic properties of neodymium magnets inside the rotor at the level as before the welding process (Fig. 11).

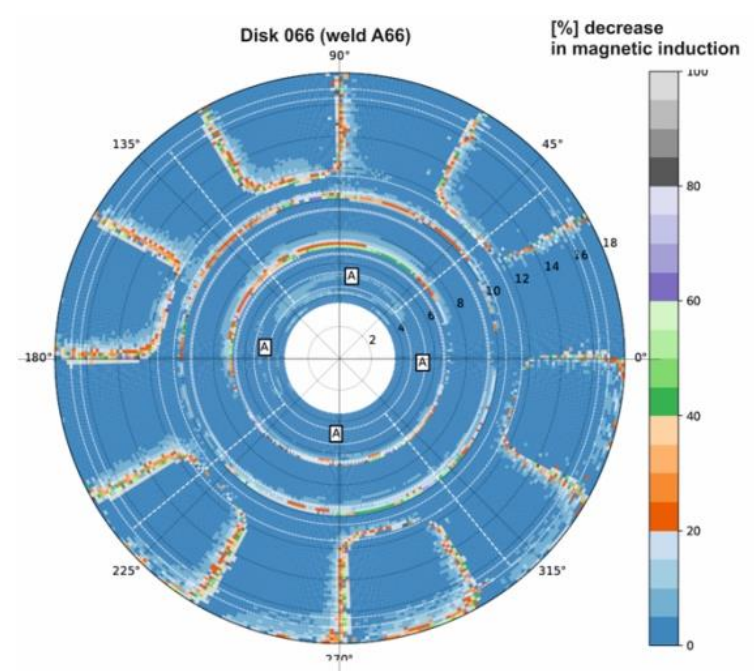

Fig. 11. Map of the distribution of changes in magnetic induction of the welded rotor with a reduced frequency of repetition of pulses - parameters A according to Table II 
The welding process of the RH-ROT heart pump rotor, due to the need to limit the heat accumulation in the welded pump rotor, is an inefficient process. The direct welding time for one of the four welds at a speed of $0.04 \mathrm{rpm}$ is 25 minutes. The direct welding time of the entire rotor is 100 minutes. It is an example of an application where the efficiency of the welding process is not the main priority in the technological process, and increasing the welding speed, although it does not directly affect the quality of the welds, directly affects the loss of usable properties of the entire welded element.

\section{References}

1. Altyntsev I.; Kurtyka P.; Darłak M.; Kustosz R. Investigation of the permanent magnetic bearings for RELIGA HEART ROT centrifugal blood pump. Int. J. Artif. Organs 2016; vol. 39(7); [CrossRef]

2. Junaid M.; Baig M.N.; Shamir M.; Khan F.N.; Rehman K.; Haider J. A comparative study of pulsed laser and pulsed TIG welding of Ti-5Al-2.5Sn titanium alloy sheet. Journal of Materials Processing Technology 2017 vol. 242; 24-38. [CrossRef]

3. Palanivel R.; Dinaharan I.; Laubscher R.F. Microstructure evolution and mechanical characterization of Nd:YAG laser beam welded titanium tubes. Materials Characterization 2017; vol. 134; 225-235.

4. Ascari A.; Fortunato A.; Guerrini G; Liverani E.; Lutey A. Long Pulse Laser Micro Welding of Commercially Pure Titanium Thin Sheets. Procedia Engineering 2017; vol. 184; 274 - 283. [CrossRef]

5. Lisiecki A. 2013431 Welding of titanium alloy by Disk laser Proceedings Volume 8703; Laser Technology 2012: Applications of Lasers; 87030T (2013) https://doi.org/10.1117/12; Tenth Symposium on Laser Technology; 2012; Szczecin; Poland.

6. Fang Y.; Jiang X.; Song T.; Mo D.; Luo Z. Pulsed laser welding of Ti-6Al-4V titanium alloy to AISI 316L stainless steel using $\mathrm{Cu} / \mathrm{Nb}$ bilayer. Materials Letters 2019; vol. 244; 1 June; 163-166 [CrossRef]

7. Chen H.; Bi G.; Lee B.Y.; Cheng C.K. Laser welding of CP Ti to stainless steel with different temporal pulse shapes. Journal of Materials Processing Technology 2016; vol. 231(5); 58-65.

8. Zhang Y.; Sun D. Q.; Gu X.Y.; Li H.M. Strength improvement and interface characteristic of direct laser welded Ti alloy/stainless steel joint. Materials Letters 2018; vol. 231; 15 November; 31-34. [CrossRef]

9. Torkamany M.J.; Malek Ghaini F.; Poursalehi R. Dissimilar pulsed Nd:YAG laser welding of pure niobium to Ti6Al-4V. Materials E Design 2014; vol. 53(1); 915-920.

10. Gursel A. Crack risk in Nd: YAG laser welding of Ti-6Al-4V alloy. Materials Letters 2017; vol. 197; 15 June; $233-235$.

11. Li C.; Li B.; Wu Z.; Qi X.; Ye B.; Wang A. Stitch welding of Ti-6Al-4V titanium alloy by fiber laser. Transactions of Nonferrous Metals Society of China 2017; vol. 27(1); 91-101. [Crossref]

12. Sarre B.; Flouriot S.; Geandier G.; Panicaud B.; de Rancourt V. Mechanical behavior and fracture mechanisms of titanium alloy welded joints made by pulsed laser beam welding. Procedia Structural Integrity 2016; vol. 2; 35693576. [CrossRef]

13. Gao X.L.; Zhang L.J.; Liu J.; Zhang J.X. Porosity and microstructure in pulsed Nd:YAG laser welded Ti6Al4V sheet. Journal of Materials Processing Technology 2014; vol. 214( 7); 1316-1325. [CrossRef]

14. Mannucci A.; Tomashchuk I.; Mathieu A.; Cicala E.; Boucheron T.; Bolot R.; Lafaye S. Direct laser welding of pure titanium to austenitic stainless steel. Procedia CIRP 2018; vol. 74; 485-490. [Hyperlink]

15. Xu P.Q. Microstructure characterization of Ti-6Al-4V titanium laser weld and its deformation. Transactions of Nonferrous Metals Society of China 2012; vol. 22 (9); 2118-2123. [CrossRef]

16. Gao X. L.; Zhang L.J.; Liu J.; Zhang J.X. A comparative study of pulsed Nd:YAG laser welding and TIG welding of thin Ti6Al4V titanium alloy plate. Materials Science and Engineering: A 2013; vol. 559 (1); 14-21. [CrossRef]

17. Casalino G.; Mortello M.; Campanelli S.L. Ytterbium fiber laser welding of Ti6Al4V alloy. Journal of Manufacturing Processes 2015; vol. 20; Part 1; 250-256.

18. Zhao S.; Yu G.; He X.; Hu Y. Microstructural and mechanical characteristics of laser welding of Ti6Al4V and lead metal. Journal of Materials Processing Technology 2012; vol. 212 (7); 1520-1527.

19. Akman E; Demir A.; Canel T.; Sınmazçelik T. Laser welding of Ti6Al4V titanium alloys. Journal of Materials Processing Technology 2009; vol. 209 (8); 3705-3713.

(C) 2019 by the authors. Submitted for possible open access publication under the terms and conditions of the Creative Commons Attribution (CC BY) license (http://creativecommons.org/licenses/by/4.0/). 